\title{
Lipid peroxidation in proliferative vitreoretinopathies
}

\section{Abstract}

Purpose To study the lipid hydroperoxide activity in vasoproliferative and fibroproliferative retinal disorders. Methods Vitreous body samples from patients undergoing vitrectomy because of proliferative vitreoretinopathy $(P V R ; n=12)$ or proliferative diabetic retinopathy (PDR; $n=15$ ), and rhegmatogenous retinal detachment/macular hole/epiretinal membranes as the comparison group (CG; $n=14$ ), were analysed for protein content and basal and induced lipid peroxidation (LPO), as determined by the thiobarbituric acid reactive substances (TBARS) test and LPO 586 commercial kit. The antioxidant activity for superoxide dismutase (SOD) and catalase (CAT) was also assayed.

Results Malondialdehyde (MDA)-like metabolites and 4-hydroxynonenal (4-HNE) mean values were first measured to assess basal LPO, and found to be significantly higher in the PVR and PDR cases than in the CG $(p \leqslant 0.0001)$. LPO induced by nicotine adenine dinucleotide phosphate iron (NADPH-Fe) was then assayed and the data showed that MDA mean values were 5-fold greater for the PVR and PDR eyes than in the case of basal LPO ( $p \leqslant 0.0001)$. SOD activity was significantly smaller in the PVR $(p=0.0010)$ and PDR $(p \leqslant 0.0001)$ groups than in the CG. CAT levels displayed significantly lower values in the PVR and PDR cases than in the CG $(p \leqslant 0.0001)$. No significant differences in free radical (FR) formation and antioxidant status between PVR and PDR patients were observed.

Conclusions Fibrovascular proliferative vitreoretinopathies correlate with increased FR formation and decreased antioxidant activity in the human vitreous body.

Key words Antioxidants, Diabetes mellitus, Free radicals, Lipid peroxidation, Vitreous body

Cell membranes are exposed to oxidative attack and lipid hydroperoxide production because of their high polyunsaturated fatty acid (PFA) content. ${ }^{1}$ Fat peroxidation is in itself a branching chain reaction that provides a steady supply of free radicals (FR), which may induce cell damage and death. ${ }^{2}$ Although molecular oxygen tetravalent reduction is the most common aerobic metabolism reaction, oxygen reactive forms are produced in many physiological and pathological metabolic pathways., ${ }^{3,4}$ Between these reactive compounds FR are generated when an oxygen atom loses one electron, thus becoming negatively charged and very unbalanced. It is then prone to capture another electron from a neighbouring molecule in order to balance its thermodynamic and structural stability, creating new FR. Superoxide anion $\left(\mathrm{O}_{2}^{-}\right)$is the first oxygen FR produced and may be followed by its protonated form, the perhydroxyl radical $\left(\mathrm{O}_{2}^{-}+\mathrm{H}^{+}=\mathrm{HO}_{2}\right)$. Hydrogen peroxide $\left(\mathrm{O}_{2}^{-}+\mathrm{O}_{2}^{-\cdot}+2 \mathrm{H}^{+}=\mathrm{H}_{2} \mathrm{O}_{2}\right.$ $+\mathrm{O}_{2}$ ) in the presence of iron leads to formation of the hydroxyl radical $\left(\mathrm{H}_{2} \mathrm{O}_{2}+\mathrm{O}_{2}+\mathrm{Fe}^{2+}=\right.$ $\mathrm{OH}^{-}+\mathrm{OH}^{-}+\mathrm{FeO}_{2}$ ), the most deleterious FR for cells and tissues. The hazardous effects of FR can be evaluated by detecting and quantifying the reaction by-products in the tested tissue, such as dienes, hydrogen peroxide, lipid peroxides, alkanes and aldehydes. ${ }^{5}$ Endogenous malondialdehyde (MDA) derives from PFA, ${ }^{6}$ with three or more double bonds and represents their peroxidation level. 4-Hydroxynonenal (4-HNE), the major representative of 4-hydroxyalkenals, is the main product formed from omega 6-PFA. ${ }^{7}$ Nowadays it is well known that lipid peroxidation (LPO) is one of the reactions set into motion as a result of FR generation in the body that mediates tissue damage and diseases.

There are intracellular and extracellular enzymatic and non-enzymatic defence mechanisms against oxidative attack that are involved in reducing or compensating FR formation. The simplest way to compensate the pro-oxidant domain is to increase the levels of antioxidants usually found in the body, including superoxide dismutase (SOD) and catalase (CAT).${ }^{1,2,5}$ Their enzymatic activities are the most relevant data in assessing both the oxidative status and tissue injury. Nevertheless, the imbalance between pro- and antioxidant sources is the origin of oxidative stress to cells and tissues.

Therefore, studies on LPO are needed in eye diseases to establish some biochemical concepts and pathogenetic mechanisms. These data could be particularly important in assessing the
C. Verdejo

P. Marco

J. Renau-Piqueras

M.D. Pinazo-Duran

Research Center University Hospital 'La Fe'

and

Ophthalmology Unit

Hospital Dr Peset-Medical

Center Monteolivete

Valencia, Spain

Ms M. Dolores PinazoDuran

Centro de Investigacion del Hospital Universitario 'La Fe' Departamento de Biología y Patología Celular Av/ Campanar 21 Valencia 46009, Spain

Tel: +34 963862700

(50411)

Fax: +34 963868718

e-mail:

pinazoduran@latinmail.com

This work was presented in part at the Annual Meeting of the Royal College of

Ophthalmologists in

Edinburgh 1996 and

Glasgow 1998, as a poster

Received: 3 March 1998 Accepted in revised form: 6 August 1998 
initial steps, as well as the long-lasting changes, occurring in the course of proliferative vitreoretinopathy (PVR) and proliferative diabetic retinopathy (PDR), which are the object of our investigations. The present study was designed to obtain vitreous samples from patients who were operated on for established PVR and PDR. A comparison group was formed of vitreous samples from eyes with non-fibrous or vascular vitreoretinal proliferation. The biomedical evidence of FR formation and their reactive metabolites is presented herein as the preliminary results of lipid peroxide determination in the most prevalent vitreoretinal diseases, by analysing MDA and 4-HNE levels using both the thiobarbituric acid reactive substances (TBARS) and LPO 586 tests. The antioxidant status was also determined in the vitreous by analysing SOD and CAT activities.

\section{Materials and methods}

Forty-five patients were initially selected for this study. All procedures conformed to the European Community guidelines for clinical trials and human research. Fortyone vitreous samples from patients ranging in age from 26 to 78 years were finally included ( $44 \%$ males, $56 \%$ females). The mean age was similar in the three study groups. We analysed FR production in 41 vitreous samples obtained during standard three-port 'pars plana' vitrectomies performed on eyes with PVR $(n=12)$ or PDR $(n=15)$. A comparison group of vitreous samples (CG; $n=14$ ) included patients with rhegmatogenous retinal detachment or epiretinal membrane and/or macular hole cases. Vitrectomies were performed with an Ocutome STTO (Alcon Surgical). One thousand millilitres of vitreous was obtained from each patient before the infusion opening and was introduced into individual cryo-Eppendorf tubes. Four aliquots were separated from each vitreous and stored at $-70{ }^{\circ} \mathrm{C}$ until processing. Samples were sonicated without any pattern dilution and processed for five biochemical techniques: protein concentration, basal and induced LPO (BLPO and ILPO, respectively) and the antioxidant activity for SOD and CAT. Protein determination was assayed by using the Bio-Rad assay with the bicinchoninic acid reagent, as described, ${ }^{8,9}$ and the results were expressed as the mean $\pm \mathrm{SD}$ for two to four different experiments.

A TBA $^{10}$ assay that analyses a whole range of agents, including secondary peroxidation products, was carried out. TBARS include malondialdehyde dimetilacetal 1,1,3,3-tetrametoxypropano (MDA) content and MDAlike metabolites. The method is based on aldehyde butanol extraction by TBA and synchronised measurement of the corresponding fluorescence emission. The reaction mixture absorbance was measured at $590 \mathrm{~nm}$ on a cytofluor against a blank containing the reagents but not the vitreous samples. Assays were repeated three to five times and the values given are the mean \pm SD for three measurements per experiment, as previously. ${ }^{11}$ We analysed the BLPO by adding to $50 \mu \mathrm{l}$ of each sample Tris maleic buffer $\mathrm{KCl}$
$5 \mathrm{mM}$ pH 7.4, bidistilled water and EDTA $10 \mathrm{mM}$. After incubation at $37^{\circ} \mathrm{C}$, SDS and $\mathrm{KCl} 0.1 \mathrm{~N}$ were also added. A mixture of diluted $2 \%$ and $20 \%$ MDA in phosphate buffer, phosphotungstic acid and TBA was finally introduced in boiling water for $60 \mathrm{~min}$. After cooling, butanol extraction was carried out by adding $1 \mathrm{ml}$ of $n$-butanol to the samples, vigorously mixing and performing the centrifugation of the specimens at $2.800 \mathrm{~g}$ for $10 \mathrm{~min}$ at $25^{\circ} \mathrm{C}$. Floating butanol layers were obtained and three samples of each processed vitreous body were deposited in a microtitre to measure emission at $590 \mathrm{~nm}$ in a cytofluor. Standard curves of MDA were assayed in parallel. The mean value for each determination was obtained and the data were processed using a BASIC program developed in our laboratory. ${ }^{12}$ Values were expressed as nanomoles per milligram protein.

ILPO was studied by means of an NADPH-iron system composed of a mixture of NADPH $40 \mathrm{mM}, \mathrm{FeCl}_{3}$ $10 \mathrm{mM}$, ADP $45 \mathrm{mM}$, which was added to the vitreous samples $(50 \mu \mathrm{l})$ immersed in Tris maleic $\mathrm{KCl} 50 \mathrm{mM} \mathrm{pH}$ 7.4 and bidistilled water to induce lipid hydroperoxide formation. MDA resulting from ILPO was assayed and measured as above. The peroxidic aldehydic product 4-HNE was assayed by the LPO 586 method purchased from Bioxytech (France), ${ }^{13,14}$ which involves a chromogenic reagent that reacts with 4 -HNE at $45^{\circ} \mathrm{C}$ when $100 \%$ methanol is added. One aliquot of each vitreous body was incubated at $45^{\circ} \mathrm{C}$ for $40 \mathrm{~min}$ in a mixture of commercialised reagents (R1: $11.4 \mathrm{mM}$ acetonitrile; R2: $10.4 \mathrm{mM}$ metanolsulfonil acid). The synchronised measurement of emission was performed on a Perkins-Elmer LS50B spectrofluorimeter $(586 \mathrm{~nm}$ absorbance) against a blank containing all the reagents except the vitreous samples. The mean values \pm SD were obtained by interpolating with standard curves developed in parallel using a BASIC program, as described above, and were expressed as nanomoles per milligram protein.

The antioxidant defence status was determined by assaying SOD and CAT enzymatic activities. SOD activity was measured by an adaptation of the method described by Bensinger and Johnson ${ }^{15}$ for eye tissues, and the technique used by Paoletti and Mocali. ${ }^{16}$ The method employed was based on the ability of SOD to inhibit a superoxide-driven reaction. It is a simple chemical reaction sequence that generates superoxide from molecular oxygen in the presence of EDTA, Mn, $\mathrm{Cl}$ and mercaptoethanol. The reagents used were triethanolamine $100 \mathrm{mM}$ and diethanolamine $100 \mathrm{mM}$ in $\mathrm{HCl}$ buffer (TDB pH 7.4), NADPH $7.5 \mathrm{mM}$, EDTA $100 \mathrm{mM}$ and $\mathrm{MnCl}_{2} 50 \mathrm{mM} \mathrm{pH} \mathrm{7,} \mathrm{and} \mathrm{mercaptoethanol}$ $10 \mathrm{mM}$. NADPH oxidation is linked to the availability of superoxide anions in the vitreous samples. SOD is added to the mixture and brings about the inhibition of nucleotide oxidation. This technique relies on the oxidation of NADPH and the corresponding measurement was spectrophotometrically accomplished. The results were expressed as the mean \pm SD for three or four experiments, as Units per milligram protein. 
CAT activity was determined by the technique described by Aebi, ${ }^{17}$ taking into account the catalytic (not the peroxidative) activity of catalase that can be measured by following the decomposition of $\mathrm{H}_{2} \mathrm{O}_{2}$. The samples were diluted in phosphate buffer $\mathrm{pH} 7.0(2 \mathrm{ml})$ and the reaction was started by addition of $\mathrm{H}_{2} \mathrm{O}_{2}(1 \mathrm{ml})$. The mixture was then stirred with a plastic paddle; the decrease in absorbance was monitored with a recorder for $c .30 \mathrm{~s}$ or at 5 or $10 \mathrm{~s}$ intervals. The remaining substrate concentration at a given moment can be determined by ultraviolet spectrophotometry. The decomposition of $\mathrm{H}_{2} \mathrm{O}_{2}$ can be followed directly by the decrease in absorbance at $240 \mathrm{~nm}$. The difference in absorbance per time unit is a measure of the CAT activity. As a reference range, the catalase activity in blood of normal subjects was found to be $313 \pm 96 \mathrm{k} / \mathrm{g}$ with respect to haemoglobin content. Data were expressed as the mean \pm SD for three or four experiments, as milliunits per milligram protein.

Statistical analysis was carried out for each experiment. The results were the mean \pm SD for three determinations and for three to five separate experiments. Data were processed by a BASIC program developed in our laboratory. ${ }^{12}$ The significance of differences between groups was analysed by SPSS / Windows (version 7.5.2S) statistical software.

Table 1. Patient characteristics

\begin{tabular}{|c|c|c|c|c|c|c|c|c|c|c|c|c|}
\hline \multirow{2}{*}{$\begin{array}{c}\text { Case } \\
\text { no. }\end{array}$} & \multirow{2}{*}{$\begin{array}{c}\text { Age } \\
\text { (years) }\end{array}$} & \multirow[b]{2}{*}{ Sex } & \multirow[b]{2}{*}{ Diagnosis $^{a}$} & \multirow[b]{2}{*}{ Onset $^{b}$} & \multicolumn{2}{|c|}{$\begin{array}{c}\text { Diabetes duration } \\
\text { (years) }\end{array}$} & \multirow{2}{*}{$\begin{array}{c}\text { Retinal } \\
\text { tears }\end{array}$} & \multicolumn{2}{|c|}{$\begin{array}{c}\text { PVR } \\
\text { (no. of quadrants) } \\
\end{array}$} & \multicolumn{3}{|c|}{ Vitreal appearance } \\
\hline & & & & & Type 1 & Type 2 & & Ant. & Post. & Pigment & Haemorrhage & Clear \\
\hline \multicolumn{13}{|c|}{ CG group } \\
\hline 1 & 37 & $\mathrm{~F}$ & RD & $6 \mathrm{~m}$ & - & - & 2 & - & & + & & \\
\hline 3 & 69 & $\mathrm{~F}$ & RD & $1 \mathrm{~m}$ & - & - & 1 & - & & & & + \\
\hline 7 & 66 & $\mathrm{M}$ & $\mathrm{RD}$ & $2 \mathrm{~m}$ & - & - & 3 & - & & + & & \\
\hline 16 & 60 & $\mathrm{~F}$ & EM & $1 \mathrm{y}$ & - & - & - & - & & & & + \\
\hline 18 & 65 & $\mathrm{~F}$ & $\mathrm{MH}$ & $3 \mathrm{~m}$ & - & - & - & - & & & & + \\
\hline 23 & 71 & $\mathrm{M}$ & $\mathrm{MH}$ & $4 \mathrm{~m}$ & - & - & - & - & & & & + \\
\hline 26 & 32 & $\mathrm{~F}$ & RD & $17 \mathrm{~d}$ & - & - & 2 & - & & & & + \\
\hline 27 & 60 & M & $\mathrm{RD}$ & $1 \mathrm{~m}$ & - & - & 1 & - & & + & & \\
\hline 32 & 64 & M & $\mathrm{MH}$ & $1 \mathrm{~m}$ & - & - & - & - & & & & + \\
\hline 35 & 55 & $\mathrm{M}$ & EM & $6 \mathrm{~m}$ & - & - & - & - & & + & & \\
\hline 37 & 66 & $\mathrm{~F}$ & $\mathrm{RD}$ & $10 \mathrm{~d}$ & - & - & 2 & - & & & & + \\
\hline 39 & 32 & $\mathrm{M}$ & RD & $2 \mathrm{w}$ & - & - & 2 & - & & & & + \\
\hline 40 & 56 & $\mathrm{M}$ & $\mathrm{RD}$ & $1 \mathrm{y}$ & - & - & 1 & - & & & & + \\
\hline 41 & 69 & $\mathrm{~F}$ & $\mathrm{MH}$ & $3 \mathrm{~m}$ & - & - & - & - & & & & + \\
\hline \multicolumn{13}{|c|}{ PVR group } \\
\hline 2 & 62 & $\mathrm{~F}$ & PVR surgery & $2 \mathrm{~m}$ & - & - & 1 & (4) & - & & & + \\
\hline 5 & 57 & $\mathrm{~F}$ & PVR surgery & $3 \mathrm{~m}$ & - & - & 1 & (3) & - & + & & \\
\hline 8 & 59 & $\mathrm{~F}$ & PVR survery & $2 \mathrm{~m}$ & - & - & 1 & (2) & (2) & + & & \\
\hline 12 & 60 & $\mathrm{~F}$ & PVR trauma & $2 \mathrm{~m}$ & - & - & 2 & - & (3) & + & + & \\
\hline 17 & 44 & $\mathrm{M}$ & PVR surgery & $7 \mathrm{~m}$ & - & - & 2 & (3) & - & + & + & \\
\hline 20 & 45 & $\mathrm{M}$ & PVR surgery & $6 \mathrm{~m}$ & - & - & 1 & (1) & - & + & & \\
\hline 21 & 52 & $\mathrm{M}$ & PVR trauma & $2 \mathrm{y}$ & - & - & 2 & (2) & - & + & & \\
\hline 29 & 74 & $\mathrm{~F}$ & PVR surgery & $1 \mathrm{y}$ & - & - & 2 & (2) & (3) & + & + & \\
\hline 30 & 66 & $\mathrm{~F}$ & PVR surgery & $10 \mathrm{w}$ & - & - & 1 & (2) & (2) & & & + \\
\hline 33 & 29 & $\mathrm{M}$ & PVR trauma & $3 \mathrm{w}$ & - & - & 2 & (1) & (2) & & & + \\
\hline 34 & 75 & $\mathrm{~F}$ & PVR surgery & $6 w$ & - & - & 1 & - & (2) & + & + & \\
\hline 36 & 78 & $\mathrm{~F}$ & PVR surgery & $3 \mathrm{~m}$ & - & - & - & (3) & - & + & & \\
\hline \multicolumn{13}{|c|}{ PDR group } \\
\hline 4 & 68 & $\mathrm{~F}$ & PDR Thromb. & $5 \mathrm{y}$ & 15 & - & - & - & - & + & & \\
\hline 6 & 42 & $\mathrm{~F}$ & $\mathrm{PDR}+\mathrm{VH}$ & $1 \mathrm{~m}$ & 20 & - & - & - & - & + & & \\
\hline 9 & 67 & $\mathrm{M}$ & $P D R+R D$ & $2 y$ & 15 & - & 2 & - & - & & + & \\
\hline 10 & 65 & $\mathrm{~F}$ & PDR & $8 \mathrm{~m}$ & - & 30 & - & - & - & + & & \\
\hline 11 & 72 & M & PDR & $3 \mathrm{~m}$ & - & 20 & - & - & - & + & & \\
\hline 13 & 62 & $\mathrm{~F}$ & $\mathrm{PDR}+\mathrm{RD}$ & $3 y$ & 25 & - & 2 & - & - & & & + \\
\hline 14 & 56 & $\mathrm{~F}$ & PDR & $2 y$ & - & 13 & - & - & - & & & + \\
\hline 15 & 24 & M & $\mathrm{PDR}+\mathrm{NG}$ & $2 \mathrm{~m}$ & 15 & - & - & - & - & + & + & \\
\hline 19 & 72 & M & $\mathrm{PDR}+\mathrm{NG}$ & $5 \mathrm{~m}$ & - & 13 & - & - & - & & + & \\
\hline 22 & 59 & M & PDR & $2 \mathrm{y}$ & - & 2 & - & - & - & & + & \\
\hline 24 & 46 & $\mathrm{M}$ & $\mathrm{PDR}+\mathrm{VH}$ & $10 \mathrm{~m}$ & 30 & - & - & - & - & & + & \\
\hline 25 & 64 & M & PDR + RD & $20 \mathrm{~m}$ & - & 23 & 1 & - & - & & + & \\
\hline 28 & 49 & $\mathrm{~F}$ & $\mathrm{PDR}+\mathrm{VH}$ & $6 \mathrm{~m}$ & 22 & - & - & - & - & + & & \\
\hline 31 & 69 & $\mathrm{~F}$ & $\mathrm{PDR}+\mathrm{VH}$ & $5 \mathrm{~m}$ & $2-$ & - & - & - & - & + & & \\
\hline 38 & 64 & $\mathrm{~F}$ & PDR & $2 w$ & - & 20 & - & - & - & & & + \\
\hline
\end{tabular}

CG, comparison group; PVR, proliferative vitreoretinopathy; PDR, proliferative diabetic retinopathy.

${ }^{a} \mathrm{RD}$, retinal detachment; EM, epiretinal membrane; $\mathrm{MH}$, macular hole; Thromb., thrombosis; VH, vitreous haemorrhage, NG, neovascular glaucoma.

bd. days; w, weeks; m, months, y, years. 


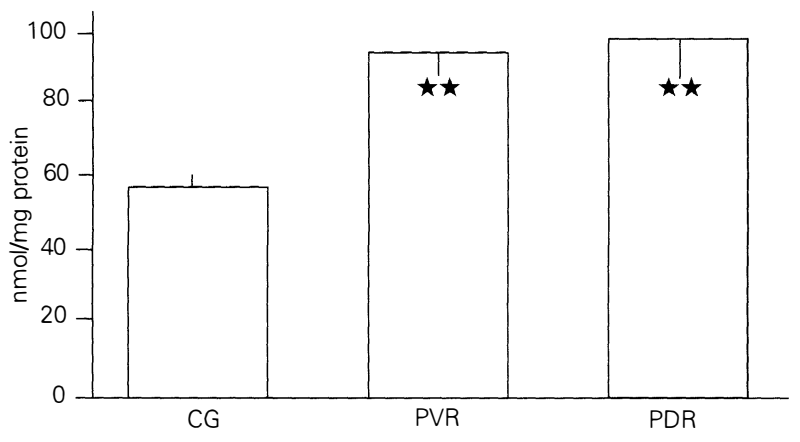

Fig. 1. Changes in basal lipid peroxidation (BLPO) in the vitreoretinopathies (nmol/mg protein). Values are the mean $\pm S D$. Asterisks indicate a significant difference $(\mathrm{p}<0.001)$ between groups.

\section{Results}

Table 1 describes origin of the samples and the characteristics of the patients.

BLPO, analysed by TBARS and expressed in MDA values (nanomol/mg tissue protein) was: $56 \pm 9$ in the CG, $92 \pm 10$ in the PVR eyes and $94 \pm 15$ in the PDR patients. Statistically significant differences between the PVR eyes and the CG $(p \leqslant 0.0001)$ and between the PDR eyes and the CG $(p \leqslant 0.0001)$ were noted, as shown in Fig. 1. 4-HNE determination also displayed significantly greater values in the PVR and PDR groups than in the CG $(p \leqslant 0.0001)$ (Table 2).

Data from the ILPO, analysed by TBARS and using an NADPH-Fe dependent system, were: $294 \pm 61$ in the CG, $473 \pm 73$ in the PVR eyes and $472 \pm 66$ in the PDR patients. Statistically significant differences between the PVR and CG cases $(p \leqslant 0.0001)$ and between the PDR and CG groups $(p \leqslant 0.0001)$ were observed. However, no significant differences were found between the PVR and PDR groups, despite the fact that the individual values were significantly higher than in the CG (Fig. 2). When compared with the BLPO, the ILPO also showed 5-fold higher MDA mean values $(294 \pm 61$ vs $56 \pm 9 \mathrm{nmol} / \mathrm{mg}$ protein in the CG, $\mathrm{p} \leqslant 0.0001 ; 473 \pm 73$ vs $92+10 \mathrm{nmol} /$ mg protein in PVR, $\mathrm{p} \leqslant 0.0001$; and $472 \pm 66$ vs $94 \pm 15$ $\mathrm{nmol} / \mathrm{mg}$ protein in PDR, $p \leqslant 0.0001)$.

The average SOD activity displayed significantly smaller values in the vitreous samples from patients suffering from PVR and PDR than in the CG ( $p=0.0010$ and $p \leqslant 0.0001$, respectively), as shown in Fig. 3 .

When CAT activity was tested, the average values were significantly higher in the vasoproliferative and fibroproliferative vitreoretinopathies than in the retinal detachment/epiretinal membranes/macular hole vitreous samples $(p \leqslant 0.0001)$, as expressed as $\mathrm{mU} / \mathrm{mg}$ protein (Fig. 4).

Table 2. Vitreal lipid peroxide levels estimated by the production of MDA-like metabolites and 4-HNE-like metabolites (LPO 586 kit)

\begin{tabular}{lll}
\hline Groups & MDA & 4 -HNE \\
\hline CG $(n=14)$ & $49 \pm 7$ & $51 \pm 10$ \\
PVR $(n=12)$ & $82 \pm 12^{* *}$ & $86 \pm 14^{* *}$ \\
PDR $(n=15)$ & $85 \pm 13^{* *}$ & $90 \pm 16^{* *}$ \\
\hline
\end{tabular}

Values are expressed in nanomoles per milligram protein. Asterisks indicate a significant difference $\left(^{* *} p<0.001\right)$ between the proliferative and the comparison human vitreous sample groups.

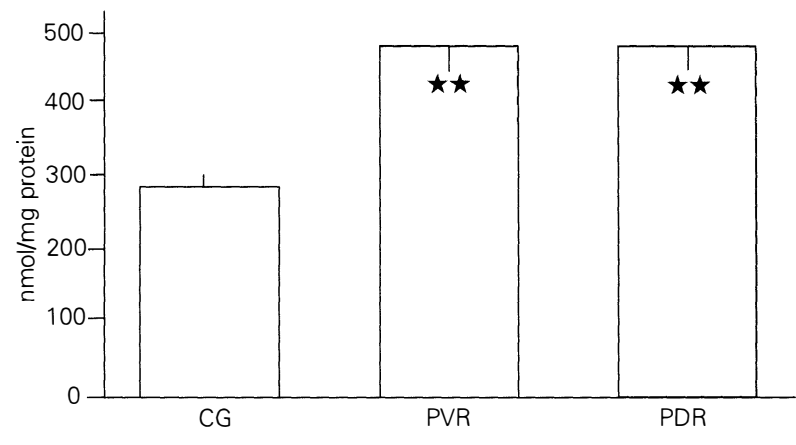

Fig. 2. Changes in induced lipid peroxidation (ILPO) in the vitreoretinopathies (nmol/mg protein). Values are the mean $\pm S D$. The results are significantly different $\left({ }^{* *} \mathrm{p}<0.001\right)$ between groups.

The relationship between SOD and CAT activity was also analysed and the values displayed significant differences in the CG versus the PVR group $(p=0.0035)$ and in the CG versus the PDR group ( $p=0.005)$.

\section{Discussion}

Our data on BLPO showed significantly higher values of MDA and MDA-like metabolites in the PVR and PDR groups than in the comparison eyes, on the TBA test. Similar results were reported by Augustin et al. ${ }^{18}$ who analysed the MDA content in the vitreous body of patients suffering from PDR. These data are also in agreement with the preliminary experiments from PVR and PDR eyes that were carried out in our laboratory. ${ }^{11}$ Controversial reports have emerged over the past few years about the reliability of the TBA test. ${ }^{12,19}$ Because of this, we additionally determined the 4-HNE content using the LPO 586 technique, a new assay recently introduced in the field of biotechnology. There were significantly higher values of this cytotoxic 4-hydroxyalkenal in the vitreous samples from patients suffering from vasoproliferative and fibroproliferative disorders than in the comparison eyes. In the latter, oxidative activity was also detected, probably as a consequence of the surgical approach, and a threshold of oxidative stress as could be expected in these pathological eyes. ${ }^{20}$ As a result of the present study we suggest that the TBARS and LPO 586 tests are valid to establish an index of human vitreous body vulnerability to lipid peroxidation.

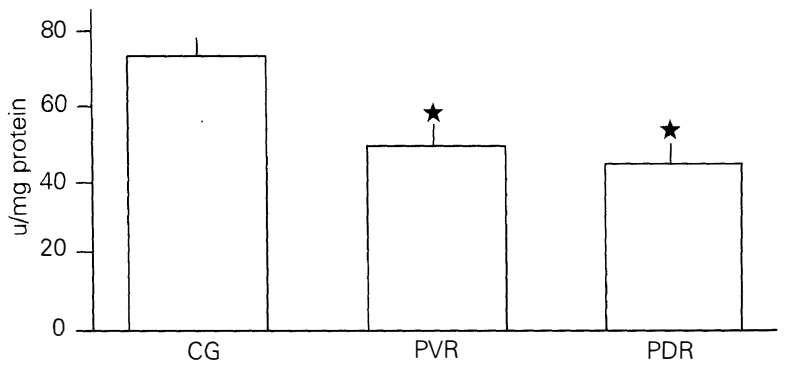

Fig. 3. Superoxide dismutase (SOD) activity in the proliferative versus non-proliferative retinopathy eyes ( $\mathrm{mU} / \mathrm{mg}$ protein). The values are expressed as the mean $\pm S D$ for three independent experiments. The results are significantly different $\left({ }^{*} \mathrm{p}<0.01\right)$ from the comparative group of eyes with non-proliferative retinopathy. 


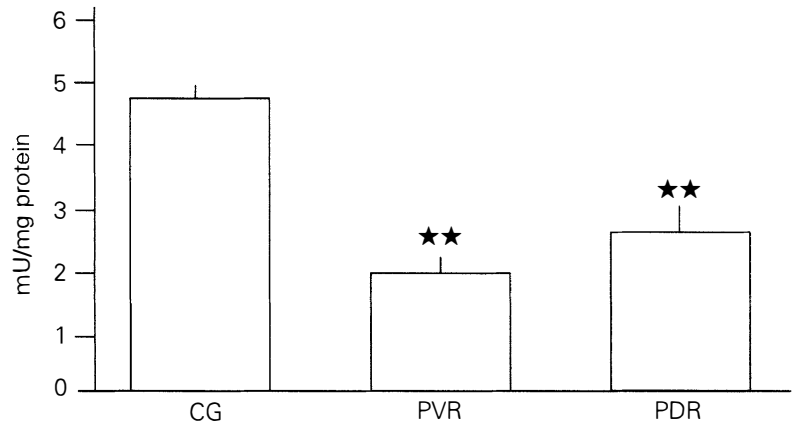

Fig. 4. Catalase (CAT) activity in the proliferative versus nonproliferative retinopathy eyes (U/mg protein). The values are expressed as the mean $\pm S D$ for three independent experiments. The results are significantly different $\left.{ }^{* *} \mathrm{p}<0.001\right)$ from the comparative group of eyes with non-proliferative retinopathy.

When lipid peroxidation was induced in the vitreous samples as a result of TBA fluorescence with the NADPH-Fe system, both the diabetic patients and individuals suffering from PVR showed 5-fold higher MDA values for the ILPO than for the BLPO.

Furthermore, under our experimental conditions oxidative attack on the ocular tissues induced by the iron system resulted in double the peroxidative aldehydes in patients suffering from vitreoretinopathies compared with the comparison group (see Fig. 2).

The increased LPO in the PVR and PDR groups as compared with the samples from eyes with nonproliferative vitreous disease is reasonably understandable. Oxidative cell injury in the course of ischaemia-reperfusion or inflammation is associated with a wide variety of anomalies ranging from alterations in signalling at low oxidant levels to death by apoptosis or necrosis at the highest levels. ${ }^{5,21}$ The results from the present study suggest that there is a noticeable FR formation in both pathologies even if the initial mechanisms causing the spontaneous release of high amounts of $\mathrm{O}_{2}^{-\cdot}$ are different. It must be taken into account that $\mathrm{O}_{2}^{-\cdot}$ generation is the first phenomenon in FR formation and could be the consequence of hypoxiaischaemia, tissue reperfusion or inflammation.

Arachidonic acid depletion, prostaglandin synthesis and phagocytosis are known to stimulate $\mathrm{O}_{2}^{-}$. synthesis by the NADPH oxidase system, much more when superoxide is in itself a positive chemotactic for neutrophil polynuclear activation. ${ }^{6,9,22-24}$ In contrast, it is not reactive enough to abstract $\mathrm{H}^{+}$from lipids. $\mathrm{OH}^{-}$has the capacity to abstract $\mathrm{H}^{+}$from PFA. A series of studies provided evidence that an iron-oxygen complex is required to trigger LPO. In fact, the addition of iron salts to PFA or to liposomes or microsomes does initiate fat peroxidation. ${ }^{3,5,21}$ The results of the increased NADPH-Fe ILP, as described here, emphasise the crucial role of $\mathrm{Fe}$ in the process and are in agreement with other reports. $3,9,18,21,25$ In addition, the higher LPO values reached in the present study coincide with the presence of vitreal bleeding in the PVR and PDR samples. This supports the hypothesis that iron availability is one of the factors that may reactivate the oxidative damage in chronic vitreoretinal disorders and subsequently the tortuous progression of the fundus signs.

The results with respect to each proliferative group, as shown in Table 2 and Figs. 1 and 2, are fairly similar. However, the lack of significant differences in FR formation between these PVR and PDR groups requires further research. Because of this, data for each pathology deserve separate discussion. From a biological viewpoint, in diabetes and other conditions in which cellular homeostasis is altered, chorioretinal hypoxia is the result of a series of cellular changes ${ }^{26}$ induced in situ by the metabolic disorder. This strongly suggests that the mechanisms of ischaemia-reperfusion create an adequate environment for FR generation and the expression of cytokines and other related molecules, ${ }^{27,28}$ leading to the progression of the vitreoretinopathy. Increased LPO was significantly detected in our group of diabetic patients in whom we had previously observed ocular fundus complications, as compared with nondiabetic individuals of similar ages. In the pathogenesis of the fibroproliferative processes, inflammation is the most relevant stage at which lipid peroxide formation can be involved..$^{22,28-30}$ It would be explained in two steps: (1) the aetiological agent causes inflammation and the underlying polynuclear neutrophil activation, (2) proteases induce FR formation via xanthin oxidase. The release of cytokines has been detected in PVR eyes and cytokines are also involved in the mechanisms of modulating the process, acting as chemotactic stimuli for inflammatory cells and fibroblasts. The cells change their apparent phenotype becoming the primary source of collagens and other extracellular matrix proteins. ${ }^{22,24}$ These phenomena might lead to the genesis of membranes and tractional bands between the retina and hyaloid, which may induce tears and retinal detachments. ${ }^{29,30}$ The results of the present study may agree with this hypothesis. This emphasises the importance of FR in the initial steps as well as in the evolution of this disease.

SOD is the main chain-breaking antioxidant, which acts in the aqueous phase by trapping $\mathrm{O}_{2}^{-\cdot} \cdot 2,31$ We have described significant differences in global SOD activity in the PVR and PDR groups as compared with the controls. We did not discriminate between the $\mathrm{Cu}-\mathrm{Zn}$ and $\mathrm{Mn}$ forms of SOD. However, total SOD activity displayed an important decrease in activity in the vitreous body from patients with PVR and PDR relative to the comparison group. Moreover, it is important to point out that CAT also showed significantly lower activity in the pathological eyes as a result of retinal proliferative phenomena. An important age-related decrease in the activity of antioxidant enzymes in the eyes has previously been described. ${ }^{32,33}$ In our study, in spite of individual differences, the mean age was quite similar between the groups with proliferative and nonproliferative disease (see Table 1, Figs. 3 and 4). The signal for the production and reactions of FR induces the formation and transport of the appropriate antioxidant to the right site. This signal might be altered in patients 
with advanced PVR and PDR and the imbalance between oxidative and antioxidative systems may trigger the cell and tissue damage occurring in these eyes. ${ }^{34}$

Taken together, our results strongly suggest that FR formation substantially increases as a result of inflammation and ischaemia-reperfusion occurring in eyes suffering from established PVR and PDR. We suggest that both mechanisms, acting at a time when FR formation and antioxidant defences become imbalanced, in the presence of iron, may trigger lipid hydroperoxide production, cell and tissue damage and death, and could lead to other molecular events involving cytokines, extracellular matrix components and diverse regulatory molecules that inexorably determine the progression of these diseases. Since FR formation and their deleterious effects on biomolecules can be avoided, or at least diminished, by blockage and removal of reactive oxygen elements, and this could be achieved by antioxidant enzymes and scavengers, further research on this possible therapeutic approach to PVR and PDR is needed. This in turn will allow more effective treatment of these damaging diseases that irreversibly lead to visual impairment in affected patients.

The authors thank Dr C. Guerri and Dr C. Montoliu for skilful technical assistance in assaying the antioxidant activities of the vitreous, Dr M. Portolés for statistical advice and Dr J. GonzalezTomás for critical reading of the manuscript.

\section{References}

1. Del Maestro RF. An approach to free radicals in medicine and biology. Acta Physiol Scand 1980;492:153-68.

2. Halliwell B, Gutteridge JMC. Lipid peroxidation, oxygen radicals, cell damage and antioxidant therapy. Lancet 1984;1:1396-7.

3. Comporti M. Lipid peroxidation: an overview. In: Poli G, Albano E, Dianzani MU, editors. Free radicals: from basic science to medicine. Turin: Birkhäuser, 1993:65-79.

4. Davis RJ, Bulkley GB, Traystman RJ. Role of oxygen free radicals in focal brain ischaemia. Fed Proc 1987;46:799-802.

5 . Fridovich I. The biology of oxygen radicals. Science 1978;201:875-80.

6. Chance B, Sies H, Boveris A. Hydroperoxide metabolism in mammalian organs. Physiol Rev 1979;59:527-605.

7. Esterbauer H, Zollner HJ, Lang J. Metabolism of the lipid peroxidation product formation 4-hydroxynonenal by isolated hepatocytes and by liver cytosolic fractions. Biochem J 1985;228:363-73.

8. Smith PK, Krohn RI, Hermanson GT, Mallia AK, Gartner FH, Provenzano MD, et al. Measurement of protein using bicinchoninic acid. Anal Biochem 1985;150:760-85.

9. Watson BD. Evaluation of the concomitance of lipid peroxidation in experimental models of cerebral ischaemia and stroke. Prog Brain Res 1993;96:69-95.

10. Buege J, Aust S. Microsomal lipid peroxidation. Methods Enzymol 1978;12:302-10.

11. Verdejo C, Marco P, Pinazo-Durán MD, Portolés M, Gonzalez-Tomás, J. Lipid peroxidation in proliferative vitreoretinopathy and vascular retinopathies. Arch Soc Esp Oftalmol 1997;72:393-400.

12. Azorín I, Bella MC, Iborra FJ, Fornás E, Renau-Piqueras J. Effects of ter-butyl hydroperoxide addition on spontaneous chemiluminescence in brain. Free Radical Biol Med 1995;19:795-803.
13. Montoliu C, Vallés S, Renau-Piqueras J, Guerri C. Ethanolinduced oxygen radical formation and lipid peroxidation in rat brain: effect of chronic alcohol consumption. J Neurochem 1994;63:1855-62.

14. Pinazo-Durán MD, Verdejo C, Montoliu C, Guerri C. Free radical formation in the eyes during chronic alcohol intoxication. Arch Soc Esp Oftalmol (in press).

15. Bensinger RE, Johnson CM. Luminol assay for superoxide dismutase. Ann Biochem 1987;110:142-5.

16. Paoletti F, Mocali A. Determination of superoxide dismutase activity by a purely chemical system based on $\mathrm{NAD}(\mathrm{P}) \mathrm{H}$ oxidation. Methods Enzymol 1990;186:209-20.

17. Aebi AH. La catalase erythrocytaire. In: Exposés annuels de biochimie médicale. 29ième série. Paris: Masson, 1969:139-66.

18. Augustin AH, Breipohl W, Böker T, Lutz J, Spitznas M. Increased lipid peroxide levels and myeloperoxidase activity in the vitreous of patients suffering from proliferative diabetic retinopathy. Graefes Arch Clin Exp Ophthalmol 1993;231:647-50.

19. Girelli D, Olivieri O, Astanzial AM, Guarini P, Trevisan MT, Bassi A, Corrocher R. Factors affecting the thiobarbituric acid test as index of red blood cell susceptibility to lipid peroxidation: a multivariate analysis. Clin Chim Acta 1994;227:45-57.

20. Saornil MA, Pastor JC. Role of intraocular irrigating solutions in the pathogenesis of post-vitrectomy retinal edema. Curr Eye Res 1987;6:1369-79.

21. Kehrer JP. Free radicals as mediators of tissue injury and disease. Crit Rev Toxicol 1993;23:21-48.

22. Luscinskas FW, Cybulsky MO, Kiely J, Peckins CS, Davis VM, Gimbrone MA Jr. Cytokine-activated human endothelial monolayers support enhanced neutrophil transmigration via a mechanism involving both endothelial-leukocyte adhesion molecule-1 and intercellular adhesion molecule-1. J Immunol 1991;146:1617-25.

23. Parola M, Albano E, Leonarduzzi G, Muraca R, Dianzani I, Poli G, et al. Evidence for a possible role of lipid peroxidation in experimental liver fibrosis. In: Poli G, Albano E, Dianzani MU, editors. Free radicals: from basic science to medicine. Turin: Birkhäuser, 1993:274-86.

24. Burke JM, Twining SS. Vitreous macrophage elicitation: generation of stimulants for pigment epithelium in vitro. Invest Ophthalmol Vis Sci 1987;28:1100-7.

25. Meneghini R, Martins EAL, Calderaro M. DNA damage by reactive oxygen species: the role of metals. In: Poli G, Albano E, Dianzani MU, editors. Free radicals: from basic science to medicine. Turin: Birkhäuser, 1993:102-12.

26. Frank RN. Etiologic mechanisms in diabetic retinopathy. In: Ryan SJ, editor. Retina, vol II. St Louis: CV Mosby, 1989:301-26.

27. Sheiki D, Itin A, Soffer D, Keshet E. Vascular endothelial growth factor induced by hypoxia may mediate hypoxiainitiated angiogenesis. Nature 1992;359:843-5.

28. Elker SG, Elner VM, Jaffe JG, Stuart A, Kunkel SL, Strieter RM. Cytokines in proliferative diabetic retinopathy and proliferative vitreoretinopathy. Curr Eye Res 1995;14:1045-53.

29. Wiedemann P, Weller M. The pathophysiology of proliferative vitreoretinopathy. Acta Ophthalmol (Copenh) 1988;189(Suppl):7-13.

30. Braudoin C, Gastaud P. La proliferation vitreoretinienne. II. Hypothèses pathogeniques. J Fr Ophtalmol 1994;17:800-11.

31. Fuchs J, Packer L. Oxidants and antioxidants. In: Sies H, editor. Oxidant stress. London: Academic Press, 1991:550-83.

32. Recasens JF, Green K. The effects of age and inflammation on antioxidant enzyme activity in the eye. Age Ageing 1992;15:114-7.

33. Rothstein M. The alteration of enzymes in aging. Modern Aging Res 1985;7:53-67.

34. Burke JM. Vitreal superoxide and superoxide dismutase after haemorrhagic injury: the role of invasive cells. Invest Ophthalmol Vis Sci 1981;20:435-41. 